\title{
ANALISANDO O DESENVOLVIMENTO PROFISSIONAL DE UM LICENCIANDO EM QUÍMICA: RELAÇÕES ENTRE CONCEPÇÕES EPISTEMOLÓGICAS E MODELOS DIDÁTICOS
}

\author{
Camila G. Passos* e José C. Del Pino
}

Departamento de Química Inorgânica, Instituto de Química, Universidade Federal do Rio Grande do Sul, 91501-970 Porto Alegre - RS, Brasil

Recebido em 28/04/2016; aceito em 24/08/2016; publicado na web em 29/09/2016

\begin{abstract}
ANALYZING THE PROFESSIONAL DEVELOPMENT OF A CHEMISTRY LICENTIATE GRADUATE: RELATIONS BETWEEN EPISTEMOLOGICAL CONCEPTIONS AND DIDACTIC MODELS. This paper comprises a case study within the scope of Chemistry teacher training that aimed to analyze the process of professional development progression of a future teacher. Therefore, we sought to identify the didactic models present in the Work Plans developed in primary schools by graduate students during supervised training. To do so, Rafael Porlán Ariza and Ana Garcia Rivero's theoretical foundation about the knowledge evolution of the teacher's professional knowledge was employed. The investigation results made evident that, during the internship period, the teacher progressed to stages deemed to be desirable to the professional development process. Moreover, evidence was found of the relation between the different academic course experiences and the teaching practices employed by the future teacher. Thus, contributions are pointed out for the comprehension about the path of professional development progression of teachers under training.
\end{abstract}

Keywords: Professional Development; Didactic Models; Epistemological Conceptions.

\section{INTRODUÇÃO}

Neste trabalho objetiva-se analisar o processo de evolução do desenvolvimento profissional ${ }^{1-3}$ de um estudante do Curso de Licenciatura em Química Noturno (CLQ) da Universidade Feral do Rio Grande do Sul (UFRGS). Este estudo compõe uma das etapas de uma investigação realizada em nível de doutorado. Tal pesquisa visou diagnosticar conquistas e desafios da matriz curricular e das ações formativas do CLQ, implementadas em 2005, frente ao conjunto de princípios e procedimentos determinados nas Diretrizes Curriculares Nacionais (DCN) para formação de professores. ${ }^{4}$

Desta forma, o objetivo maior deste é identificar as relações entre os modelos didáticos utilizados por um dos licenciandos com as concepções epistemológicas que os fundamentam. $\mathrm{O}$ aluno foi investigado durante os estágios de docência. Ele foi da primeira turma que cursou toda a organização curricular em vigência desde 2005. Ademais, pretende-se verificar as formas de contribuição do conjunto de atividades formativas vivenciadas pelo licenciando durante o CLQ para o seu processo de desenvolvimento profissional.

É pertinente salientar que o termo desenvolvimento profissional $^{1-3}$ vem sendo utilizado com frequência no campo educacional, pois caracteriza de forma mais abrangente o processo de formação de um educador. Os autores ${ }^{1-3}$ destacam que se trata de um conceito que supera as divisões entre formação inicial e continuada e expressa evolução e continuidade. Evolução, pois o desenvolvimento profissional é considerado um processo que se constrói à medida que os professores adquirem experiência, sabedoria e consciência profissional. Continuidade, pois o desenvolvimento das concepções epistemológicas e práticas profissionais provém de experiências formais e informais, adquiridas ao longo da vida escolar e social e que podem ser aperfeiçoadas no decorrer da carreira.

Desta forma, alguns trabalhos apontam que professores em formação podem progredir em seu desenvolvimento profissional, no sentido de aproximarem seus procedimentos didáticos de perspectivas

*e-mail: camila.passos@ufrgs.br construtivistas e investigativas. ${ }^{5}$ Conforme relatos na literatura, as ações formativas que mais favorecem o processo de aperfeiçoamento profissional são aquelas que possibilitam a investigação sobre os problemas práticos profissionais, ou seja, sobre as rotinas de sala de aula. ${ }^{5}$ Sendo assim, o processo evolutivo pode ser favorecido através da analise crítica, das práticas educacionais e das concepções epistemológicas que as fundamentam, sob orientação dos professores formadores e com o aporte de referênciais teóricos. ${ }^{6-8}$

Conforme relatos na literatura, o estudo das concepções epistemológicas dos professores envolve a análise integrada do sistema de crenças educacionais desses profissionais. ${ }^{6,7}$ Tais crenças são, por exemplo, suas convicções sobre o papel do professor e do aluno nos processos de ensino e de aprendizagem e sobre o papel social da escola, com as suas concepções científicas, ${ }^{8,9}$ como a compreensão sobre a natureza da Ciência e o status do conhecimento científico.

Neste sentido, as concepções epistemológicas podem ser consideradas como ferramentas de suporte ou obstáculos ao desenvolvimento profissional docente. Haja vista que elas têm papel organizador da prática e estruturador do conhecimento profissional, embasam, assim, os modelos didáticos utilizados pelos professores e futuros professores. ${ }^{5,10}$ Neste âmbito, investigações sobre as concepções epistemológicas dos professores em formação têm contribuído com explicações sobre o porquê de muitas ações formativas não terem um impacto significativo na mudança das práticas docentes implementadas nas Escolas de Educação Básica. ${ }^{5,10,11}$ Desta forma, salienta-se que as concepções epistemológicas influenciam a compreensão dos futuros professores sobre o que é aprender a ensinar, sendo significativas para a interpretação das experiências formativas vivenciadas nos cursos de licenciatura.

Alguns pesquisadores da área de formação de professores descrevem que os docentes de Ciências, em especial, são resistentes à mudança de suas concepções espistemológicas, visto que elas foram estruturadas social e culturalmente de forma não reflexiva no período escolar. ${ }^{12,13}$ Além disso, essas concepções são muitas vezes reforçadas por grande parte das atividades dos programas de formação das instituições universitárias, que ainda são norteados pelo reducionismo 
epistemológico academicista e pelo absolutismo racionalista. ${ }^{5,10} \mathrm{O}$ reducionismo epistemológico academicista visa enfatizar o saber disciplinar como o mais relevante para o ensino, ignorando e menosprezando os demais saberes que constituem o conhecimento profissional do professor. ${ }^{5}$ Já o absolutismo racionalista preconiza que o verdadeiro conhecimento está no conjunto de teorias produzidas pela racionalidade científica e que aprender a ser professor significa apropriar-se dos significados verdadeiros das disciplinas. ${ }^{5}$ Há, desta forma, o estabelecimento de uma relação mecânica e linear entre a teoria e a prática profissional. Isso conduz os futuros professores a trabalharem os conteúdos de forma expositiva em sala de aula, assim como lhes expuseram na formação acadêmica, o que significa uma visão simplista do ensino, do professor e de sua função. ${ }^{5}$

Assim, avanços na realidade escolar e principalmente no ensino de Ciências são possíveis, mas, para isso, os professores precisam desenvolver um conhecimento profissional menos influenciado pela cultura dominante. Este processo está condicionado à modificação das concepções absolutistas e reducionistas dos professores formadores e dos futuros professores. ${ }^{5}$ Os autores destacam que estas concepções são coerentes com a cultura escolar em que foram formados, estando longe dos princípios sócio-construtivistas, críticos e relativistas que fundamentam os modelos contemporâneos de ensino. ${ }^{5}$

Salienta-se que as metodologias de ensino investigativas e construtivistas, diferente das tradicionais, concebem os alunos como sujeitos de aprendizagem. Eles possuem conhecimentos sobre os fenômenos em estudo e são capazes de participar efetivamente na investigação de problemas que possibilitem o enriquecimento destes conhecimentos, sendo o professor o orientador desta investigação. Neste âmbito, a linha de pesquisa em que este trabalha se encontra torna-se relevante para fundamentar a elaboração de programas de formação que efetivamente favoreçam práticas docentes condizentes com os intentos das pesquisas da Didática das Ciências, assim como das DCN. ${ }^{5,12,13}$

Dentre alguns estudos sobre as mudanças das concepções epistemológicas dos professores de Ciências, verifica-se que os autores se referem à ideia de progressão das concepções, estabelecendo estágios intermediários para acompanhar o desenvolvimento profissional. Como no caso das investigações com professores em formação continuada, onde foi possível verificar uma mudança gradual de concepções empiristas e behavioristas para posições intermediárias como o positivismo lógico e o cognitivismo. Os autores destacam, porém, que uma mudança drástica para o construtivismo é um processo difícil e complexo. ${ }^{14}$ Os pesquisadores apontam que a evolução gradual das concepções dos professores está relacionada a dois tipos de obstáculos: os de contexto, como a organização escolar e o status da profissão; e os relativos ao próprio docente, como as suas concepções epistemológicas. ${ }^{8,14}$

A mudança de concepções e práticas dos professores de Ciências é um processo difícil e gradual para o qual existe pouca informação sobre os itinerários de progressão. ${ }^{5}$ Os autores relatam que ainda há indeterminações sobre as condições que mais favorecem o processo de evolução do conhecimento profissional, sendo esta uma das causas da complexidade do estudo e um dos fatores que intensificam a relevância deste tema de pesquisa. ${ }^{5}$

Posto isto, justifica-se este trabalho como um exercício de aproximação a uma abordagem sistemática, que busca analisar de forma articulada as concepções epistemológicas do futuro professor e as atividades formativas que compõem o CLQ, para, assim, poder avaliar as suas práticas de ensino. Frente a estes objetivos, utiliza-se da Hipótese de Progressão do conhecimento profissional, ${ }^{15}$ concebida como uma teoria sobre como o conhecimento profissional pode se complexificar em direção a um nível considerado como desejável. Os autores descrevem que se trata de uma estratégia com pretensão de melhoria significativa e progressiva dos sistemas de ideias pré-existentes dos professores e não da sua mera substituição, como se descreve a seguir.

\section{Hipótese de Progressão do conhecimento profissional}

Embora existam variados critérios para caracterizar os modelos didáticos pessoais dos professores, ${ }^{16,17}$ neste estudo utiliza-se as categorias propostas por Rafael Porlán Ariza e Ana Garcia Rivero. ${ }^{15}$ Os autores identificam tais modelos de acordo com as concepções epistemológicas que os fundamentam, analisando-os conforme uma perspectiva evolutiva dentro da Hipótese de Progressão do conhecimento profissional.

Rafael Porlán Ariza e Ana Garcia Rivero ${ }^{15}$ realizaram uma ampla pesquisa utilizando o questionário INPECIP (Inventario de Creencias Pedagógicas y Científicas) para elaborar a hipótese geral de progressão do conhecimento profissional. Os autores estabeleceram uma gradação referente à evolução do conhecimento profissional em três níveis hierárquicos: desde perspectivas mais simplificadoras, reducionistas, estáticas e acríticas, correspondentes a do modelo didático Tradicional; perpassando níveis intermediários, como o modelo Tecnológico e o Espontaneísta, que superam em parte o tradicional, mas que ainda apresentam obstáculos a serem superados; até outras perspectivas mais coerentes com modelos alternativos e construtivistas, como o modelo Investigativo, considerado como desejável. Todavia, os autores afirmam que sua hipótese não se constitui em uma receita definitiva e acabada, nem um itinerário inevitável, mas uma proposta que defende um planejamento evolutivo do conhecimento profissional onde se considera importante tanto o processo quanto o produto. ${ }^{15}$

Na proposta de transição e evolução de modelos didáticos norteadas na Hipótese de Progressão do conhecimento profissional ${ }^{15}$ são consideradas as seguintes quatro categorias de análise: Conteúdos Escolares; Uso Didático das Perspectivas dos Alunos; Tipos de Atividades e Recursos Didáticos; e Avaliação. Estas quatro categorias referem-se a como os professores ou futuros professores abordam os conteúdos escolares em seus Planos de Trabalho; como utilizam as perspectivas dos alunos; quais os tipos de atividades e recursos didáticos são priorizados; e quais as formas de avaliação utilizadas. Conforme as características dos procedimentos didáticos descritos nas quatro categorias, pode-se identificar o modelo didático adotado pelos professores, dentre os quatro modelos didáticos que compõem os três níveis hierárquicos do conhecimento profissional, como se descreve a seguir.

No primeiro nível do conhecimento profissional, encontra-se o modelo didático Tradicional. Este modelo é fundamentado por concepções epistemológicas absolutistas e reducionistas sobre a Ciência. No modelo didático Tradicional: ${ }^{15}$

* Os Conteúdos Escolares são formulados em sequências lineares, fechadas, rígidas e estáticas. Referências são feitas a dados e conceitos expressados em um único nível de formulação, sem estabelecimento de relações e conexões com o conhecimento dos alunos, ou com alguma problemática socioambiental ou cultural. Desta forma a Ciência é a única referência na determinação do conhecimento escolar;

* O Uso Didático das Perspectivas dos Alunos não é considerado, pois os fins educativos implícitos podem representar a adaptação social dos alunos, ou o doutrinamento cultural e a transmissão dos valores dominantes;

* Os Tipos de Atividades e Recursos Didáticos caracterizam-se pela transmissão verbal do professor e o uso quase que exclusivo do livro didático. Os procedimentos didáticos são desenvolvidos no sentido de aplicar ou verificar a teoria, sendo ordenadas em função dos conteúdos, sendo propostas de maneira uniforme a toda turma, dando pequena participação aos alunos; 
* A Avaliação é entendida como comprovação do grau de memorização mecânica dos conteúdos, com o uso de provas ou exames como instrumentos básicos. Assim se avalia o produto e não o processo, portanto, a avaliação é entendida como um mecanismo de poder, delegada socialmente e ligada a uma imposição autoritária do saber.

No segundo nível do conhecimento profissional encontram-se o modelo didático Tecnológico e o Espontaneísta. No modelo didático Tecnológico mantém-se uma concepção de fundo absolutista da Ciência, porém utiliza-se o enfoque empiro-indutivista. ${ }^{15}$ Logo, neste modelo:

* Os Conteúdos Escolares são a adaptação dos conteúdos das disciplinas científicas à escola. Eles são organizados e sequenciados de acordo com os objetivos terminais e obrigatórios, sendo a Ciência a referência fundamental na determinação do conhecimento escolar;

* O Uso Didático das Perspectivas dos Alunos é considerado apenas na exploração inicial, como fins motivacionais, pois a finalidade educativa está baseada na neutralidade, busca-se ensinar adequadamente as ciências;

* Os Tipos de Atividades e Recursos Didáticos caracterizam-se pelo predomínio de um plano de atividades progressivo, fechado e detalhado em função dos objetivos buscados, onde os alunos exercem protagonismo na execução das atividades, mas não em sua elaboração;

* A Avaliação prevê uma medição rigorosa do grau de execução dos objetivos traçados, por meio de provas aplicadas no início e no final do processo.

Ainda no segundo nível do conhecimento profissional, encontra-se o modelo didático Espontaneísta. Nele, rompe-se com o absolutismo epistemológico, adotando-se posições relativistas do conhecimento em geral e particularmente do conhecimento científico. ${ }^{15}$ Sendo assim, neste modelo:

* Os Conteúdos Escolares conceituais são determinados a partir dos interesses ou objetos de estudo que se negocia com os alunos, pois é dada grande importância aos procedimentos e atitudes;

* O Uso Didático das Perspectivas dos Alunos é continuamente considerado, pois se pretende que os alunos adquiram uma formação voltada ao cotidiano, de maneira autônoma e crítica;

* Os Tipos de Atividades e Recursos Didáticos caracterizam-se pelo predomínio de um plano genérico de atividades baseadas no ensaio e erro, com diferentes tipos de tarefas, mas sem uma sequência determinada, onde os alunos são participantes tanto da elaboração quanto da execução das atividades;

* A Avaliação visa analisar a dinâmica da aula através da participação dos alunos e das observações e impressões do professor, pois a aprendizagem dos alunos não é objeto direto da avaliação.

No terceiro nível do conhecimento profissional, considerado como desejável, encontra-se o modelo didático Investigativo. Este modelo é fundamentado por concepções epistemológicas complexas e relativas da Ciência, em um planejamento ideológico crítico e em uma perspectiva construtivista e evolutiva do conhecimento. Desta forma, no modelo didático Investigativo: ${ }^{15}$

* Os Conteúdos Escolares são resultados da integração de distintos tipos de conhecimento de natureza epistemológica diferente (científico, social, cotidiano), organizando-se com caráter hipotético em tramas de conceitos, procedimentos e atitudes e em níveis de complexidade ascendente. Nesta perspectiva, os conteúdos são organizados em torno de problemas de investigação;

* O Uso Didático das Perspectivas dos Alunos é continuamente considerado, pois as finalidades educativas direcionam-se à formação integral dos alunos como futuros cidadãos, abandonando perspectivas propedêuticas e disciplinares dos níveis anteriores;

* Os Tipos de Atividades e Recursos Didáticos são organizados a partir de pautas construtivistas, como, por exemplo, o reconhecimento de problemas, a tomada de consciência dos alunos sobre as próprias ideias e o contraste crítico de tais ideias com outras informações. A sequência prévia é flexível, reformulando-se em função da evolução real das concepções dos alunos;

* A Avaliação é entendida, em curto prazo, como uma investigação do grau de ajuste entre as hipóteses curriculares do professor, a aprendizagem dos alunos e a dinâmica da aula, enquanto em longo prazo, é útil para a reelaboração de um modelo didático pessoal.

Frente a estes apontamentos, destaca-se que o conhecimento profissional considerado como desejável, pelos autores e nesta investigação, pode ser compreendido como um conhecimento epistemologicamente diferenciado e interessado, pois engloba atitudes e valores que visam à transformação do contexto escolar e profissional.

Alguns autores escrevem que a passagem de um nível a outro do conhecimento profissional depende de uma série de remodelagens do conhecimento prévio de forma qualitativa ${ }^{5,14,18}$. A manifestação dos diferentes níveis está atrelada "ao grau de tomada de consciência, controle e superação relativa de diversos obstáculos que dificultam a compreensão dos processos de ensino e aprendizagem em um nível de complexidade superior". ${ }^{15}$ (p. 93)

A Hipótese de Progressão do conhecimento profissional vem sendo utilizada promissoramente para acompanhar o desenvolvimento profissional de professores de Ciências em programas de formação inicial e continuada. ${ }^{5,19}$ De acordo com relatos da literatura, o estudo da evolução dos modelos didáticos presentes nas produções escritas e orais dos professores em formação e das concepções epistemológicas que fundamentam tais modelos, além de possibilitar a discussão sobre a evolução do conhecimento profissional, auxilia na identificação das intervenções metodológicas que mais favorecem o processo de progressão. ${ }^{10,20,21}$

\section{METODOLOGIA}

A investigação descrita neste trabalho tem natureza qualitativa, pois se analisou um contexto de sala de aula frente às suas particularidades, subjetividades e complexidades. Para tanto, a pesquisa foi desenvolvida em uma estrutura analítica integrada através de um Estudo de Caso. O Estudo de Caso deve ser utilizado quando se investiga fenômenos sociais complexos em suas condições contextuais. ${ }^{22}$ Para tanto, os autores esclarecem que é favorável coletar dados utilizando diferentes instrumentos, para relacioná-los e confrontá-los, a fim de melhor compreender os fenômenos estudados. ${ }^{23}$

Nesse sentido, primeiramente, efetivou-se a análise documental ${ }^{22}$ dos Planos de Trabalho elaborados por um licenciando durante os Estágios Curriculares Supervisionados. O licenciando que participou desta investigação era integrante da primeira turma que cursou toda a organização curricular do CLQ em vigência desde 2005. O futuro professor, assim como seus colegas, respondeu a um questionário, no início do primeiro estágio, que visava à elaboração do perfil acadêmico e profissional da turma. Entende-se que informações referentes ao histórico acadêmico e profissional dos licenciandos podem contribuir para a discussão sobre o processo de desenvolvimento profissional. No segundo estágio, os licenciandos responderam a um questionário composto de questões abertas, que visava identificar a realização das expectativas dos licenciandos quanto ao período dos estágios, e as formas de contribuição do CLQ para o desenvolvimento da conduta docente adotada por eles nos estágios.

É pertinente ressaltar que, desde a reformulação curricular, realizada no CLQ ${ }^{24,25}$ no ano de 2005, até 2011, as 420 horas de estágios curriculares supervisionados estavam distribuídas na forma de duas disciplinas: Estágio em Ensino de Química IA de 12 créditos e o Estágio em Ensino de Química IIA de 16 créditos. Destaca-se que no decorrer do texto serão apresentadas, de forma objetiva, demais características sobre o conjunto de ações formativas do CLQ. 
Neste trabalho foram analisados os Planos de Trabalho e as respostas do licenciando aos dois questionários aplicados. O licenciando foi chamado de Zef, para manter em sigilo sua verdadeira identidade. Este estudante foi selecionado utilizando como critério a compatibilidade de horários das aulas que foram ministradas nas escolas com a disponibilidade dos pesquisadores para acompanhá-lo. Além disso, considerou-se a concordância do mesmo, a autorização da escola, dos alunos e seus responsáveis, pois as aulas ministradas por ele, em umas das turmas em que estagiou, foram filmadas por um dos pesquisadores.

Os planejamentos elaborados pelo licenciando foram implementados durante os Estágios Curriculares Supervisionados em Escolas de Educação Básica da rede pública estadual de ensino na cidade de Porto Alegre no ano letivo de 2011. No total foram registradas 60 horas-aula durante os dois estágios. Para acompanhar as aulas como observador participante, ${ }^{22}$ elaborou-se um Diário de Campo ${ }^{26}$ como instrumento de coleta de dados e guia de investigação sobre a efetivação das atividades identificadas nos Planos de Trabalho nos dois estágios.

Os dados coletados foram analisados e interpretados segundo o sistema de categorias de codificação proposto por Bogdan e Biklen. ${ }^{23}$ É pertinente salientar que, para atingir os objetivos deste estudo, utilizou-se das quatro categorias de análise esquematizadas na proposta de transição e evolução de Modelos Didáticos norteadas na Hipótese de Progressão do conhecimento profissional. ${ }^{15}$ As categorias são: Conteúdos Escolares; Uso Didático das Perspectivas dos Alunos; Tipos de Atividades e Recursos Didáticos; Avaliação. A partir dessas quatro categorias de análise, buscaram-se aproximações dos Planos de Trabalho do licenciando, com as características apontadas para cada categoria. Na sequência, relacionaram-se as características das ações formativas do CLQ, analisadas em estudos anteriores, ${ }^{24,25} \mathrm{com}$ os Modelos Didáticos utilizados pelo licenciando. Isso foi feito em busca de identificar o sinergismo entre as atividades vivenciadas no CLQ, as concepções epistemológicas do licenciando e as práticas desenvolvidas nas escolas em que ele estagiou.

\section{RESULTADOS E DISCUSSÃO}

\section{O licenciando Zef}

O licenciando Zef tinha 32 anos de idade no período da investigação. Quanto à formação e a atuação profissional, a licenciatura em Química foi o seu primeiro curso superior. Ele cursou técnico em Mecânica e trabalhava na área de formação há 10 anos. Zef informou que havia atuado como professor de Química durante 3 meses em uma escola da rede particular de ensino. Quando questionado sobre os motivos que influenciaram a escolha pelo CLQ, o licenciando apontou que buscava realização profissional e que tinha aptidão pelas ciências exatas.

\section{Modelos Didáticos do Licenciando Zef - Estágio IA}

No primeiro estágio, o licenciando Zef elaborou um Plano de Trabalho para duas turmas do $2^{\circ}$ ano do ensino médio de uma Escola da rede pública estadual de Porto Alegre. Conforme os relatos de Zef, seus planejamentos foram estruturados visando trabalhar os conteúdos sobre a constituição da matéria e a estequiometria das reações. Esses planos seguiam o acordo firmado com a professora regente das turmas, as descrições do Projeto Político Pedagógico da Escola e as orientações do professor orientador do estágio.

Zef estruturou seu Plano de Trabalho numa sequência de oito aulas de três períodos semanais, apresentando inicialmente, em âmbito geral, uma justificativa para seus planejamentos, os objetivos gerais, assim como os conteúdos, metodologia e as formas de avaliação. Na sequência, ele descreveu o objetivo de cada aula, as atividades, conteúdos, recursos didáticos e os instrumentos avaliativos que foram utilizados.

Na apresentação geral do Plano de Trabalho, Tabela 1S, pode-se verificar que o licenciando destacou que integraria conhecimentos de diferentes áreas em seus planejamentos. Além disso, utilizaria de distintas representações e exemplos do cotidiano para contextualizar os conteúdos da Química e despertar nos alunos o interesse pelo estudo desta ciência.

Conforme os registros no Diário de Campo, destaca-se que Zef, realmente, implementou atividades que possibilitaram a participação dos alunos nas aulas. Das oito aulas que foram acompanhadas, seis priorizaram momentos de debate e socialização para tratar dos conceitos científicos. Na maioria dos momentos de aula, Zef buscou possibilitar o diálogo entre os alunos e entre ele e os alunos, abrindo espaço para a exposição de dúvidas sobre os conteúdos e acontecimentos cotidianos ligados aos exemplos trabalhados, como se pode verificar na descrição da metodologia das aulas 01 e 02 , e 03 e 04, nas Tabelas $2 \mathrm{~S}$ e 3S, respectivamente, como ilustra-se com os seguintes trechos:

[Aula 01 e 02] Metodologia: Questionar os alunos sobre as diferenças entre peso e massa; Discutir como chegar aos valores de peso na terra e na lua; [...].

[Aula 03] Metodologia: Introduzir o estudo das reações químicas perguntando: O que é, e como representar uma reação de combustão? Cite possíveis reagentes e produtos envolvidos? [...].

Desta forma, percebe-se que o licenciando propôs atividades coerentes aos objetivos elencados no Plano de Trabalho. Ainda que o conhecimento científico seja visivelmente considerado como referente fundamental, outros aspectos também foram contemplados nos planejamentos de Zef, tais como a interação do científico com o cotidiano e a integração dos âmbitos conceituais, atitudinais e procedimentais.

Segundo Zabala ${ }^{27}$ os conteúdos são de natureza conceitual, procedimental e atitudinal. São conceituais por conterem conceitos, fatos e princípios, isto é, por expressarem o que se deve saber sobre. Os procedimentais se referem a técnicas e métodos, ao que se deve saber fazer. Enquanto os atitudinais abrangem valores, atitudes e normas.

Neste âmbito, os objetivos atitudinais, como o trabalho colaborativo, posicionamento crítico e respeito com a opinião dos colegas, tornaram-se coerentes entre as proposições e objetivos buscados, como nas atividades das aulas 03 e 04, Tabela 3S. No aspecto procedimental, Zef privilegiou diversas formas de atuação do aluno, como: manipulação de objetos; atividades de pesquisa; resolução de exercícios no quadro; argumentação oral e escrita; reconhecimento e interpretação dos fenômenos estudados nas aulas; e associação de situações cotidianas com os conteúdos científicos. Além disso, buscou incentivar a postura autônoma dos alunos com a abertura de espaço para eles exporem suas dúvidas, ideias e proporem exercícios.

Diante do exposto salienta-se que os planejamentos de Zef apresentam características que se aproximam de dois modelos didáticos quanto à categoria Conteúdos Escolares. Primeiramente ao modelo didático Tecnológico, ${ }^{15}$ por deixar subentendido que o referente fundamental para os conhecimentos escolares é oriundo da Química e que tais conhecimentos devem ser adequados a uma linguagem escolar. Segundo, por propor uma sequência de atividades que explicitamente visavam "a compreensão do conteúdo pelo aluno", como o próprio licenciando destacou ao descrever a metodologia que utilizaria no Plano de Trabalho, Tabela 1S. 
Zef também propôs inúmeras atividades experimentais (demonstrativas ou práticas) que implicitamente objetivavam elucidar ou comprovar as definições estudadas, coforme os registros do Diário de Campo das aulas 02, 03 e 04 e conforme os objetivos e metodologias descritos nos planos das referidas aulas, nas Tabelas $2 \mathrm{~S}$ e $3 \mathrm{~S}$, de acordo com os trechos abaixo:

[Aula 01 e 02] Metodologia: [...] Questionar quantos pregos cabem em um copo cheio de água, visando discutir e contextualizar a descontinuidade da matéria; [...].

[Aula 04] Metodologia: Prática 01 - Neutralização: Eu orientarei que eles deverão seguir o procedimento descrito no relatório fornecido para cada grupo. Eu lerei com eles passo a passo os procedimentos e discutirei como calcular a massa de bicarbonato de sódio obtida experimentalmente em nossa prática e como representar o que foi feito na forma de uma equação química. [...].

Entende-se que este conjunto de atividades fundamenta-se numa concepção tecnicista, ${ }^{5}$ pois tem como finalidade reproduzir uma técnica experimental para que os alunos cheguem às teorias previamente elaboradas pela Ciência.

Todavia, mesmo que muitos dos objetivos do Plano de Trabalho de Zef contemplassem definições conceituais da Química, ele propôs atividades que integraram os referentes cotidianos, sociais, ambientais e econômicos, organizados nos âmbitos conceituais, procedimentais e atitudinais. Ele também demonstra considerar que distintos tipos de conhecimentos de naturezas epistemológicas diferentes compõem os conhecimentos escolares ao propor atividades que: contextualizaram o conteúdo científico com exemplos do cotidiano; integraram representações microscópicas e macroscópicas para discutir os conceitos científicos com os alunos; visavam a pesquisa e discussão de questões sobre as diferentes aplicações comerciais e industriais dos compostos e reações estudados, e sobre o impacto ambiental gerado pelo seu uso. É importante salientar que estas características são próximas do modelo didático Investigativo. ${ }^{15}$

Zef, em nenhum momento de seu Plano de Trabalho, apontou que seria o centralizador do conhecimento científico, muito menos, citou momentos de explanação ou transmissão direta dos conteúdos. Pelo contrário, como se verificou nas aulas que foram acompanhadas, o licenciando demonstrou querer associar o dia a dia dos alunos com as definições conceituais que estavam sendo trabalhadas. Com isso, ele estava visando à aprendizagem dos conhecimentos escolares a partir dos conhecimentos de seus alunos sobre os conteúdos e fenômenos que estavam sendo estudados, além de instigá-los a participar das aulas. Sendo assim, entende-se que Zef considera o papel epistêmico ${ }^{11}$ dos conhecimentos prévios dos alunos no processo de aprendizagem, pois considerou as ideias e interesses dos alunos para o desenvolvimento das atividades, através de vários questionamentos em aulas do tipo expositivo-dialogadas, visando a complexificação destes conhecimentos.

Neste sentido, destaca-se como exemplo deste posicionamento a discussão realizada na aula 01 , Tabela $2 \mathrm{~S}$, sobre a diferença das definições de massa e peso. Aqui o licenciando descreve que esclarecerá o que é "massar" e "pesar", porém, que alertará seus alunos sobre a utilização usual do termo pesar. Posto isto, evidencia-se que implicitamente o licenciando demonstra considerar as ideias prévias dos alunos como elemento cognitivo do processo de aprendizagem, visando complexificar os conhecimentos dos alunos, relacionando os fenômenos discutidos com as representações e teorias que seriam trabalhadas. Logo, infere-se que os planejamentos de Zef se aproximam do modelo didático Investigativo ${ }^{15}$ para a categoria Uso Didático da Perspectiva dos Alunos, pois há convergências das práticas empreendidas, com as concepções de perspectiva relativistas e construtivistas que fundamentam este modelo.

Conforme os registros do Diário de Campo e dos dados identificados nos Plano de Trabalho de Zef, enfatiza-se que ele concebe que nem sempre a cultura cotidiana tem que necessariamente ser substituída pelas concepções da cultura científica. Ele parece acreditar que tais culturas possam coexistir e que serão utilizadas conforme o contexto em questão.

Todavia, percebe-se uma mescla de concepções que remetem a dois modelos distintos quanto à categoria Tipos de Atividades $e$ Recursos Didáticos. Por um lado, o licenciando apresenta e realiza atividades diversificadas, mas fechadas, e que possuem características de um modelo tecnicista ${ }^{15}$. Como exemplo, destaca-se a proposição de práticas experimentais orientadas (roteiros prontos) para se chegar a um ponto pré-determinado, como na aula 04, Tabela $3 \mathrm{~S}$, ou visando ilustrar e comprovar os conceitos científicos estudados, como na aula 01 (volume dos objetos e descontinuidade da matéria), Tabela $2 \mathrm{~S}$. Todavia, estas atividades englobam momentos de discussão que oportunizam a reflexão e socialização das ideias, a elaboração de hipótese e a integração de referentes de diferentes áreas de conhecimento. Logo, apresentam características que remetem ao nível de transição desejável, ou seja, o modelo Investigativo ${ }^{15}$. Conforme os trechos:

[Aula 01 e 02] Metodologia: [...] Apresentar e revisar algumas definições (átomo, massa, $\mathrm{n}^{\circ}$ atômico) e instigá-los a construir comigo as definições para as grandezas químicas, buscando já relacioná-las, para facilitar a compreensão das relações estequiométricas que serão estudadas nas próximas aulas; [...]. [Aula 04] Metodologia: [...] O relatório contém questões teóricas, como o porquê do valor encontrado ser diferente do expresso no rótulo? Qual a ação do comprimido utilizado na prática no organismo humano? Quais outras substâncias podem ser usadas para mesma função? Quais os riscos da utilização frequente deste tipo de medicamento? Que opções naturais eles conhecem que substituem a utilização deste tipo de medicamento? Qual outra aplicação do bicarbonato de sódio em nosso dia a dia? [...].

Quanto ao processo de Avaliação mais uma vez identificou-se uma mescla de concepções, porém de cunho tradicional e investigativo, como se ilustra nos trechos descritos abaixo, e nas Tabelas $1 \mathrm{~S}$ a 3S.

[Aula 06] Avaliação: [...] Simulado da prova (em dupla, para promover a discussão e reflexão sobre os conteúdos e como forma de estudo para a prova parcial).

[Aula 07] Avaliação: [...] Prova parcial (individual e sem consulta, valendo $30 \%$ da nota trimestral).

[Aula 08] Avaliação: Prova trimestral (elaborada com questões objetivas, conforme combinado com a professora regente, valendo $50 \%$ da nota trimestral).

Diante das diversas formas de avaliação verificadas no Plano de Trabalho de Zef, percebe-se que o licenciando utilizou de um processo avaliativo evolutivo quanto aos conceitos e procedimentos, baseando-se em diferentes instrumentos (relatórios, provas, resolução de exercícios, participação nas discussões, pesquisas, realização de experimentos) e momentos de avaliação. Além disso, no âmbito atitudinal o licenciando considerou a avaliação de atitudes como comprometimento, respeito, criatividade e participação com dúvidas, ideias e exemplos. Logo, demonstrou que também considera o processo avaliativo como processual, por auxiliá-lo no diagnóstico da evolução da interação entre as ideias da Ciência, dos alunos e do 
professor. Diante do exposto, entende-se que os planejamentos de Zef se aproximam do modelo didático Investigativo. ${ }^{15}$

Entretanto, não se identifica aspectos quanto à avaliação das atividades propostas, nem momentos para a autoavaliação dos alunos e do professor. Além disso, as provas elaboradas por Zef apresentavam características de um instrumento sancionador e qualificador. Elas eram constituídas apenas de questões que abordavam os conteúdos de forma diretiva e classificatória, envolvendo cálculos estequiométricos, sem relações com as diferentes representações e temáticas trabalhadas em aula. Segundo Zef, apenas a prova trimestral foi elaborada seguindo orientações da professora regente das turmas. Salienta-se que na Escola em que ele realizou o estágio, os alunos são avaliados obrigatoriamente com duas provas. Uma trimestral com o peso de $50 \%$ da nota total e outra que fica a critério do professor. Logo, mesmo com liberdade de escolha, o licenciando elaborou instrumentos que visavam majoritariamente avaliar a consecução dos objetivos conceituais propostos. Sendo assim, frente ao expressivo percentual destes instrumentos na nota trimestral, considera-se que o processo avaliativo adotado por Zef também apresenta proximidade com o modelo didático Tradicional. ${ }^{15}$

De acordo com os registros no Diário de Campo, Zef conseguiu efetivar seus planejamentos no primeiro estágio, de forma convergente com as características das categorias identificadas no Plano de Trabalho.

\section{Modelos Didáticos do Licenciando Zef - Estágio IIA}

No segundo estágio, Zef elaborou um Plano de Trabalho para três turmas do $1^{\circ}$ ano do ensino médio da mesma Escola em que realizou o primeiro estágio. O Plano de Trabalho de Zef contemplou tópicos sobre ligações químicas, reações químicas e funções inorgânicas, numa sequência de oito aulas de três períodos semanais. $\mathrm{O}$ licenciando estruturou seus planejamentos a partir de temas como água e problemas ambientais e a partir de aplicações comerciais de alguns ácidos, bases, sais e óxidos. Desta forma, conseguiu trabalhar os tópicos que a professora regente das turmas selecionou para o período do estágio, dentre aqueles que o Projeto Político Pedagógico da Escola relacionava para o terceiro trimestre.

Destaca-se que os planejamentos de Zef mantiveram algumas características verificadas nos planejamentos do primeiro estágio, tais como: a forma de apresentação do Plano de Trabalho; a integração e contextualização dos conteúdos da Química; e a proposição de objetivos dos âmbitos conceituais, procedimentais e atitudinais, como se ilustra na Tabela 4S, e com os seguintes trechos:

[Plano de Trabalho do Estágio II A] Objetivos Gerais: [...] Abordar os conteúdos de maneira contextualizada; [...] Despertar o hábito da leitura e interpretação de textos que possuam conteúdo cientifico e tecnológico; [...] Incentivar os alunos a investigar curiosidades sobre o conteúdo abordado e a sua relação com outras ciências, buscando ampliar seus conhecimentos. Incentivá-los a analisar, argumentar e posicionar-se criticamente; [...].

Da mesma forma, a prática docente de Zef, conforme os registros no Diário de Campo, manteve-se direcionada à utilização de distintas representações para o estudo dos fenômenos e conteúdos científicos. Também manteve-se a proposição de aulas do tipo expositivo-dialogadas, oportunizando a participação dos alunos na elaboração e realização das atividades.

Enfatiza-se que, no segundo estágio, Zef demonstrou grande preocupação em estruturar planejamentos que integrasse o conteúdo científico a uma temática social, ambiental, comercial ou industrial.
Ademais, observa-se que diferentemente do primeiro estágio, não houve o predomínio do referente científico sobre os demais, pois as aulas e atividades foram estruturadas a partir de temáticas que englobavam os conteúdos, e não o contrário, como verificado no estágio anterior. Além disso, as atividades com essas finalidades foram propostas para serem realizadas majoritariamente em aula, possibilitando a discussão e reflexão sobre temas como consumo consciente da água, problemas ambientais e utilização de aditivos químicos, como se ilustra com as descrições das aulas 01 e 02, e, 03 e 04, nas Tabelas 5S e 6S, respectivamente, e com os trechos abaixo:

[Aula 01 e 02] Metodologia: Leitura de trechos do artigo: As águas do planeta Terra (QNE de 2001) para introduzir o estudo sobre a água, seu ciclo, suas reservas no mundo, propriedades e importância em nossa vida (cada dupla receberá o texto adaptado impresso e cada aluno lerá um parágrafo para a turma); [...].

[Aula 03] Metodologia: Leitura do texto: A chuva ácida (Livro do GEPEC, 1995); Aplicação de um questionário sobre o texto, os conceitos envolvidos e as opiniões pessoais dos alunos sobre o tema (tarefa em grupo); [...].

[Aula 06] Metodologia: Aula expositivo-dialogada sobre as regras de nomenclatura, conceitos e questionamentos levantados sobre os rótulos dos produtos de limpeza, higiene pessoal e de alimentos analisados (que serão escolhidos e trazidos pelos alunos); Análise da função inorgânica, aplicação (conservante, acidulante, emulsificante, etc.) e riscos à saúde dos diferentes aditivos químicos identificados nos rótulos que os alunos trouxerem; Ampliar o estudo sobre as teorias de ácido e base, relacionando as já estudadas com a de Lewis; Realização de exercícios;

Frente aos dados analisados, destaca-se que os planejamentos de Zef possibilitaram o diálogo entre os diferentes conteúdos científicos trabalhados (como a relação entre as propriedades periódicas e ligações químicas, nas aulas 01 e 02 , Tabela $5 \mathrm{~S}$, e das funções inorgânicas e reações químicas, nas aulas 03 e 04, Tabela 6S), não seguindo uma lógica linear e rígida, como frequentemente são estruturados os planejamentos de trabalho para estes tópicos. Salienta-se ainda que, no segundo estágio, além de não fazer distinção entre os diferentes referentes que compõem o conhecimento escolar, o licenciando elaborou atividades que explicitamente visavam complexificar o conhecimento conceitual dos alunos e desenvolver os objetivos atitudinais e procedimentais propostos na apresentação geral do seu Plano de Trabalho.

No conjunto de registros do Diário de Campo e dos planejamentos, identifica-se que, com relação aos objetivos de âmbito atitudinal, Zef primou por incentivar a autonomia dos alunos. Isso foi feito através de atividades em que eles defenderam suas ideias, demonstraram seus interesses, relacionaram conteúdos científicos com aplicações práticas do cotidiano, do meio comercial e industrial, elaboraram soluções para impactos ambientais, trabalharam em grupo e respeitaram o posicionamento dos colegas. Quanto ao âmbito procedimental, Zef priorizou o desenvolvimento de atividades que possibilitaram diversas formas de atuação do aluno, desde a manipulação de objetos e rótulos, atividades de pesquisa, argumentação oral e escrita, até a proposição de exemplos, de exercícios e de substâncias para os testes das aulas experimentais.

Diante do exposto, considera-se que Zef progrediu quanto à concepção do objetivo das aulas práticas, pois o próprio licenciando destacou que realizaria experimentos "para relacionar os conteúdos estudados em aula com os fenômenos presentes no dia a dia", Tabela 4S, e não visando apenas a compreensão dos conteúdos e a 
ilustração das teorias científicas como verificado no primeiro estágio. Conforme relatos na literatura, metodologias de ensino investigativas, que envolvem de forma conjunta estudos teóricos, experimentais e interpretativos, possibilitam a aproximação do aluno com a cultura científica de forma mais efetiva. ${ }^{12}$

Com estas evidências infere-se que, no segundo estágio, Zef demonstrou possuir uma concepção sistêmica e complexa da realidade e do meio escolar, por não enfatizar apenas a relevância do conhecimento da disciplina e sim da integração e contextualização dos distintos conhecimentos que compõem o conhecimento escolar. Neste sentido, conclui-se que na categoria Conteúdos Escolares os planejamentos de Zef aproximam-se do modelo didático Investigativo. ${ }^{15}$

Quanto aos conhecimentos prévios dos alunos, verifica-se que, mais uma vez, Zef demonstrou considerar o papel epistêmico de tais no processo de aprendizagem. O licenciando apresentou uma proposta de trabalho, e uma conduta docente, ainda mais centrada na participação dos alunos, buscando envolvê-los através de atividades em que eles tivessem como expressar suas ideias e interesses. Participação tanto em âmbito da tomada de decisão, como na aula 04, Tabela $6 \mathrm{~S}$, onde os alunos escolheram os exemplos e a forma de apresentar a pesquisa sobre reações de combustão e de fermentação, como na proposição das atividades segundo seus interesses (aula 03 e 06, quando os alunos testaram, analisaram e discutiram sobre produtos e rótulos que eles escolheram e trouxeram de casa). Destaca-se também as discussões das aulas expositivo-dialogadas que visavam à socialização das ideias e a complexificação dos conhecimentos dos alunos, coforme os registros do Diário de Campo. Logo, conclui-se que o licenciando novamente se aproxima do modelo didático desejável (Investigativo ${ }^{15}$ ) para a categoria Uso Didático da Perspectiva dos Alunos.

Para a categoria Tipos de Atividades e Recursos Didáticos, entende-se que Zef progrediu em direção a uma proposta de trabalho coerente a do modelo didático Investigativo. ${ }^{15}$ Nos planejamentos deste segundo estágio, identifica-se um grande número de atividades dinâmicas e flexíveis, como a análise de rótulos (aula 06), a leitura de textos sobre temáticas sociais, ambientais e tecnológicas (aula 02 e 03, Tabela 5S), os problemas de investigação e as discussões sobre os resultados das pesquisas (aula 03 e 04, Tabela 6S), como verifica-se nos trechos abaixo:

[Aula 03] Metodologia: [...] Discussão das respostas no grande grupo; Realização da prática do repolho roxo, testando materiais que os alunos trarão de casa [...] e entrega do relatório; Apresentar a teoria de ácido e base de Arrhenius após a discussão sobre a prática.

[Aula 04] Metodologia: [...] Cada grupo pesquisará sobre um tipo de reação e apresentará para a turma. Cada reação será pesquisada por dois grupos, visando uma discussão sobre diferentes respostas obtidas.

Considera-se que estas atividades envolveram a integração de referentes de diferentes áreas de conhecimento, o trabalho em grupo, a interação entre os alunos, entre os alunos e professor-estagiário, e entre os alunos e diversos materiais e recursos didáticos. Sendo assim, infere-se que as atividades foram organizadas com grande proximidade de uma concepção de perspectiva relativista e construtivista que fundamentam o modelo didático Investigativo. ${ }^{15}$

Sobre o processo avaliativo, observa-se que Zef utilizou diversos instrumentos (relatórios, prova, resolução de exercícios, participação nas discussões, pesquisas, realização de experimentos, leituras) coerentes com os objetivos conceituais, procedimentais e atitudinais propostos em seu Plano de Trabalho. Zef novamente demonstrou considerar que o processo de aprendizagem é contínuo e processual, pois utilizou de diferentes momentos de avaliação, visando diagnosticar a complexificação das ideias dos alunos através da interação interpessoal entre eles. Neste sentido, compreende-se que para o licenciando o processo de aprendizagem é favorecido quando ocorrem discussões e reflexões, sobre os diferentes referentes que compõem o conhecimento escolar, entre os alunos, e entre os alunos e o professor. Como exemplo desta concepção e da respectiva conduta docente, destacam-se os trechos sobre avaliação, nos Planos de Trabalho transcritos nas Tabelas 4S a 6S, como ilustra-se:

[Aula 03] Avaliação: Participação na leitura e na prática (contribuição com materiais); Relatório; Organização do grupo nas discussões; Envolvimento com as tarefas; Realização das atividades; Crescimento conceitual.

Desta forma, mesmo que Zef não tenha proposto atividades de autoavaliação para os alunos sobre o processo de aprendizagem e sobre as aulas ministradas, entende-se que ele utilizou de um processo avaliativo formativo e não sancionador. Faz-se esta consideração, pois a prova utilizada trazia questões que abordavam os conteúdos de forma integrada, trazendo relações com as diferentes representações e temáticas trabalhadas em aula. Além disso, verificou-se a coerência entre as estratégias utilizadas em aula e os instrumentos avaliativos, e que o percentual da nota da prova parcial foi menor do que o do estágio anterior. Sendo assim, compreende-se que houve uma progressão dos planejamentos de Zef quanto ao processo avaliativo, pois o licenciando considerou que os demais instrumentos avaliativos são tão significativos quanto a prova para acompanhar o desenvolvimento dos seus alunos. Logo, infere-se que os planejamentos de Zef se aproximam do modelo didático Investigativo ${ }^{15}$ para a categoria Avaliação.

De forma geral, conforme os registros no Diário de Campo, Zef empreendeu seus planejamentos no segundo estágio de forma convergente com as características das categorias identificadas no Plano de Trabalho.

\section{Evolução dos Modelos Didáticos e o reflexo das formas de contribuição do CLQ para o desenvolvimento profissional do licenciando}

Conforme o conjunto de dados analisados, evidencia-se que o licenciando Zef, durante o período dos estágios, progrediu para o nível considerado como desejável na Hipótese de Progressão do conhecimento profissional. ${ }^{15}$ Desde o primeiro estágio, Zef demonstrava possuir concepções de níveis intermediários do itinerário de progressão, como a empiro-indutivista (modelo didático Tecnológico), mescladas com a relativista (modelo didático Investigativo), quanto às categorias Conteúdos Escolares e Tipos de Atividades e Recursos Didáticos. Além disso, o licenciando valorizou os conhecimentos prévios dos alunos sobre as teorias e fenômenos estudados, demonstrando que considerava o papel epistêmico destes no processo de aprendizagem dos seus alunos, aproximando-se, assim, da perspectiva construtivista para a categoria Uso Didático da Perspectiva dos Alunos. No segundo estágio, Zef aproximou-se fortemente do modelo didático Investigativo para as quatro categorias de análise, pois ele empreendeu uma prática docente norteada nos princípios da investigação e construção do conhecimento.

Nesse âmbito, é importante relatar que, conforme a experiência profissional dos autores deste trabalho como professores formadores nos estágios desde a implementação do currículo vigente, o nível de desenvolvimento profissional identificado para Zef é pouco comum. Destaca-se que nos resultados apresentados na literatura ${ }^{5,8,10,14,20}$ a maioria dos professores ou futuros professores, que evoluem dentro 
do itinerário de progressão, aproxima-se de níveis intermediários do desenvolvimento profissional.

Frente a esse contexto, entende-se que o conjunto de concepções epistemológicas de Zef, identificadas no primeiro estágio, serviu como ferramenta para a sua progressão em direção a níveis mais avançados do processo de desenvolvimento profissional. Considerando o caráter subjetivo do processo e a influência da história de vida do licenciando, conclui-se que um conjunto de fatores em sinergismo pode ter contribuído para o aperfeiçoamento do seu conhecimento profissional.

O licenciando conseguiu reformular suas concepções e práticas durante os dois semestres de estágio, a partir das reflexões orientadas e norteadas na literatura. As atividades desenvolvidas nos estágios supervisionados no CLQ priorizam ações de investigação sobre as rotinas de sala de aula, à luz de aportes teóricos, visando à análise crítica sobre as interações entre as concepções e práticas dos futuros professores. ${ }^{25}$

Quando questionado sobre a realização das expectativas em relação aos estágios, o licenciando descreveu que suas expectativas foram totalmente atingidas, conforme se transcreve: "Foram atingidas totalmente. Encontrei respaldo justamente em relação às dificuldades encontradas na escola" (Zef).

Conforme relatos na literatura, as atividade formativas direcionadas ao estudo dos problemas práticos profissionais favorecem o processo de desenvolvimento profissional, por possibilitarem a análise entre a inter-relação entre as concepções epistemológicas e as práticas docentes empreendidas. ${ }^{5-8}$

Acrescido as contribuições do período dos estágios, cabe salientar que Zef já havia atuado como professor por três meses. Logo, mesmo sendo uma breve experiência, pode ter favorecido o processo de análise sobre as práticas docentes empreendidas, sobre suas crenças e concepções e sobre as alternativas de intervenções metodológicas que foram trabalhadas durante o período inicial do primeiro estágio. Nesse sentido, compreende-se que Zef, mesmo sendo um professor em formação, aceitou e adotou práticas docentes contemporâneas, por ter iniciado o seu processo de desenvolvimento profissional desde os primeiros contatos com a profissão. Esta hipótese está fundamentada na compreensão de que o desenvolvimento profissional é evolutivo e contínuo, ou seja, necessita que o futuro professor tenha adquirido consciência profissional mínima, para que possa analisar suas concepções e práticas, à luz da literatura, visando o aperfeiçoamento do seu conhecimento profissional. ${ }^{1-3}$

Entende-se que o processo de progressão das concepções e práticas depende, consideravelmente, da identificação da necessidade, e da disponibilidade de mudança nas rotinas de sala de aula. Alguns autores destacam que os professores devem querer e acreditar nas reformulações pretendidas para a educação, para que os resultados das pesquisas educacionais atinjam o meio escolar. ${ }^{5,8,14}$

Ademais, Zef escolheu o curso de licenciatura em química visando à realização profissional, mesmo possuindo formação técnica e atuando na área, no período em que participou da investigação.

Todavia, é pertinente salientar que conforme estudos anteriores, os procedimentos didáticos utilizados no CLQ, principalmente nas disciplinas de conhecimentos específicos de Química e área afins, aproximam-se do modelo didático Tradicional. ${ }^{24}$ Os resultados apurados apontam que os conteúdos de Química e áreas afins não são trabalhados com o enfoque nas situações reais da futura prática profissional dos licenciandos, evidenciando a pequena efetivação da reforma curricular implementada em 2005, quanto ao trabalho da dimensão prática, conforme determinam as $\mathrm{DCN}{ }^{4}$

$\mathrm{O}$ próprio licenciando, quando questionado sobre as características do CLQ que mais influenciaram na sua prática docente, relata que foi difícil não seguir o modelo de ensino vivenciado durante o curso. Conforme Zef
"O curso de licenciatura é, por mim, considerado muito técnico, pra mim foi muito difícil não abordar os conteúdos de forma técnica. O curso no geral é pouco didático, cada um tem que buscar recursos próprios para aprender se quiser aprovar. Destaco as boas contribuições das disciplinas práticas, especialmente as de orgânica, e cadeiras de educação".

Desta forma, infere-se que o licenciando investigado demonstra aproximar-se de um estágio elevado do processo de desenvolvimento profissional. Mesmo vivenciando um curso norteado no reducionismo epistemológico academicista e no absolutismo racionalista, ele conseguiu adotar uma conduta docente coerente com suas concepções epistemológicas de cunho relativistas e construtivistas e não utilizar o modelo de ensino e aprendizagem vivenciado na maioria das disciplinas do CLQ.

\section{CONCLUSÃO}

Como guisa de conclusão, verificou-se que durante o período dos estágios, Zef avançou no processo de desenvolvimento profissional no sentido de aproximar-se fortemente, no segundo estágio, do modelo didático Investigativo, para as quatro categorias de análise. Destacase que o licenciando empreendeu uma prática docente norteada numa perspectiva construtivista e evolutiva do conhecimento, pois priorizou o trabalho dos conhecimentos escolares de forma integrada às temáticas sociais, ambientais e econômicas; utilizou de distintas representações para o estudo dos fenômenos e conteúdos científicos; elaborou atividades que favoreceram complexificar os conhecimentos conceituais, atitudinais e procedimentais dos alunos; considerou os conhecimentos prévios dos alunos, favorecendo a participação ativa destes nas aulas; priorizou práticas investigativas que possibilitaram a socialização de ideias e conceitos, e, a interação entre alunos e professor; e elaborou diferentes instrumentos avaliativos, para acompanhar a evolução dos estudantes.

Destaca-se que a conduta docente de Zef não é comum entre professores em formação, ${ }^{10,20}$ visto que este licenciando atingiu o nível considerado como desejável dentro do itinerário da Hipótese de Progressão do conhecimento profissional. ${ }^{15}$ Frente a esse contexto, entende-se que um conjunto de fatores pode ter contribuído para que o licenciando atingisse tal nível de evolução do processo de desenvolvimento profissional docente. Salienta-se que o sinergismo entre a disponibilidade de mudança das concepções e práticas, associada as atividades reflexivas e críticas vivenciadas nos estágios, assim como suas experiências pessoais e profissionais anteriores favoreceram o aperfeiçoamento do conhecimento profissional do licenciando.

Ademais, desde o primeiro estágio o licenciando demonstrou possuir convicções sobre o papel do professor e do aluno no processo de ensino e aprendizagem coerentes com os princípios sócio-construtivistas. Da mesma forma, compreender o conhecimento científico numa perspectiva crítica e relativista. Sendo assim, infere-se que o conjunto de concepções epistemológicas do licenciando Zef serviu como ferramenta de suporte à sua progressão para níveis mais avançados do processo de desenvolvimento profissional.

Assim, conclui-se que o desenvolvimento profissional é favorecido quando futuros professores apresentam interesse em analisar suas concepções epistemológicas e práticas docentes, a fim de buscar as inter-relações entre tais e as possibilidades apontadas nos aportes teóricos educacionais para atender as demandas do processo de ensino e aprendizagem das Ciências. Desta forma, salienta-se a relevância de atividades formativas que favoreçam a aproximação dos licenciandos com o contexto escolar. Assim, os futuros professores podem iniciar o processo de reflexão sobre a prática profissional, antes dos estágios de docência, no que se refere às suas possibilidades e dificuldades. 
Sendo assim, essas ações podem contribuir para o desenvolvimento de uma consciência profissional mínima, para que os licenciandos possam reformular suas concepções epistemológicas e adotar modelos didáticos de perspectiva investigativa em suas práticas.

\section{MATERIAL SUPLEMENTAR}

Alguns trechos dos Planos de Trabalho do licenciando Zef, utilizados neste trabalho, estão disponíveis em http://quimicanova.sbq. org.br, na forma de arquivo PDF, com acesso livre.

\section{REFERÊNCIAS}

1. Imbernón, F.; Formação Docente e Profissional: formar-se para a mudança e a incerteza, Cortez: São Paulo, 2009.

2. Marcelo, C.; Sísifo. Revista das Ciências da Educação 2009, 8, 7.

3. Nóvoa, A.; O regresso dos Professores. Desenvolvimento Profissional de Professores para a Qualidade e para a Equidade da Aprendizagem ao longo da Vida, Ministério da Educação de Portugal: Lisboa, 2008.

4. Ministério da Educação. Conselho Nacional de Educação. Institui as Diretrizes Curriculares Nacionais para a Formação de Professores da Educação Básica, em nível Superior, curso de licenciatura de graduação plena. Resolução CNE/CP 01, 2002.

5. Porlán, R.; Martín del Pozo, R.; Rivero, A.; Harres, J.; Azcárate, P.; Pizzato, M.; Enseñanza de Las Ciencias 2010, 28, 31.

6. Beach, R.; Pearson, D.; Teach. Teach. Educ. 1998, 14, 337.

7. Kagan, D. M.; Rev. Educ. Res. 1992, 62, 129.

8. Mellado, V.; Sci. Educ. 1997, 6, 331.

9. Ledermann, N. G.; Zeidler, D.L.; Sci. Educ. 1987, 71, 721.

10. Luft, J. A.; Roehrig, G.H.; Electronic Journal of Science Education. 2007, 11, 38.
11. Harres, J. B. S; Pizzato, M. C.; Sebastiany, A. P.; Predebon, F.; Fonseca, M. C.; Revista Brasileira de Ensino de Ciência e Tecnologia. 2008, 1, 95.

12. Carvalho, A. M. P.; Gil-Pérez, D.; Formação de Professores de Ciências: tendências e inovações, Cortez: São Paulo, 2006.

13. Schnetzler, R.; Quim. Nova. 2002, 25, 14.

14. Flores, F.; López, A.; Gallegos, L.; Barojas, J.; Int. J. Sci. Educ. 2000, 22, 197.

15. Porlán, R.; Rivero, A.; El conocimiento de los profesores, Díada: Sevilla, 1998.

16. García Pérez, F. F.; Revista Bibliográfica de Geografía y Ciencias Sociales. 2000, 207, 1 .

17. Novais, R. M.; Marcondes, M. E. R.; Anais do XIV Encontro Nacional de Ensino de Química, Curitiba, Brasil, 2008.

18. Mansour, N.; International Journal of Environmental \& Science Education. 2009, 4, 25.

19. Harres, J. B. S; Pizzato, M. C.; Contexto \& Educação. 2007, 22, 51.

20. Predebon, F.; Del Pino, J. C.; Investigações em Ensino de Ciências. 2009, 14, 237.

21. Rodrigues, C. G.; Krüger, V.; Soares, A.C.; Cienc. Educ. 2010, 16, 415.

22. Lüdke, M.; André, M. E. D. A.; Pesquisa em Educação: Abordagens Qualitativas, EPU: São Paulo, 1986.

23. Bogdan, R. C.; Biklen, S. K.; Investigação qualitativa em educação: uma introdução à teoria e aos métodos, Porto: Portugal, 1994.

24. Passos, C. G.; Del Pino, J. C.; Journal of Science Education-Revista de Educación en Ciencias. 2012, 13, 34.

25. Passos, C. G.; Del Pino, J. C.; Revista Contexto \& Educação. 2013, 28, 72.

26. Porlán, R.; Martín, J.; El diario del profesor: Un recurso para la investigación en el aula, 6 ed. Díada: Sevilla, 1998.

27. Zabala, A.; A prática educativa: como ensinar, Artes Médicas: Porto Alegre, 1998. 